\title{
Predicting osteoporosis with body compositions in postmenopausal women: a non-invasive method
}

\author{
Wei-Hsiu Hsu ${ }^{1,2,3+}$, Wei-Bin Hsu' ${ }^{3 \dagger}$, Chun-Hao Fan ${ }^{3}$ and Robert Wen-Wei Hsu $u^{1,2,3^{*}}$
}

\begin{abstract}
Background: The prevalence of osteoporosis is rising steadily as the aging population increases. Bone mineral density (BMD) assessment is a golden standard to establish the diagnosis of osteoporosis. However, the accessibility and radiation exposure limited its role in community screening. A more convenient approach for screening is suggested.
\end{abstract}

Methods: A total of 363 postmenopausal women over the age of 50 were included in this study and assessed with the body composition [including fat-free mass (FFM), fat mass (FM), and basal metabolic rate (BMR)] and BMD. Normal distributions and correlation coefficients among variables were calculated using the Shapiro-Wilk test and Pearson's correlation analysis, respectively. A receiver operating characteristic (ROC) curve was plotted, and the area under ROC curves (AUC) was determined to obtain the optimal cutoff values of the body composition variables for osteoporosis prediction.

Results: The correlation coefficient of FFM, FM, FM ratio, and BMR with femur neck T-score was 0.373, 0.266, 0.165, and 0.369 , respectively, while with spine $T$-score was $0.350,0.251,0.166$, and 0.352 , respectively $(p<0.01$ for all). FFM, FM, and BMR showed an optimal cutoff value of $37.9 \mathrm{~kg}, 18.6 \mathrm{~kg}$, and $1187.5 \mathrm{kcal}$, respectively, for detecting osteoporosis.

Conclusions: The present study provided a model to predict osteoporosis in postmenopausal women, and the optimal cutoff value of FFM, FM, and BMR could be calculated in the Asian population. Among these factors, BMR seemed a better predictor than others. The BMR could be a target for exercise intervention in postmenopausal women for maintaining or improving BMD.

Trial registration: ClinicalTrials.gov, NCT02936336. Retrospectively registered on13 October 2016.

Keywords: Basal metabolic rate, Fat-free mass, Fat mass, Osteoporosis, Postmenopausal women

\footnotetext{
* Correspondence: wwh@cgmh.org.tw

${ }^{\dagger}$ Wei-Hsiu Hsu and Wei-Bin Hsu contributed equally to this work.

'Department of Orthopaedic Surgery, Chang Gung Memorial Hospital, No. 6,

West Section, Chia-Pu Road, Pu-Tz City, Chiayi 613, Taiwan

${ }^{2}$ School of Medicine, Chang Gung University, Taoyuan City, Taiwan

Full list of author information is available at the end of the article
}

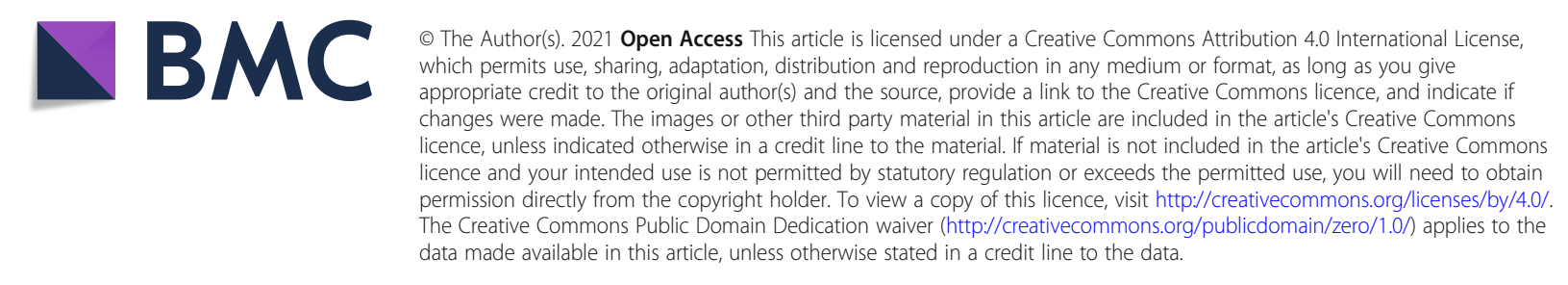




\section{Background}

Osteoporosis is a common and silent skeletal disease characterized by bone mineral density (BMD) loss, resulting in fragile bone and high fracture risk [1-3]. It is more prevalent in postmenopausal women as a result of estrogen deficiency. Indeed, the prevalence of osteoporosis is rising steadily resulting from the aging population [4]. However, osteoporosis also occurs in healthy premenopausal women, resulting from various factors such as unsuitable diet, inadequate physical activity, medications, and smoking $[5,6]$. In 2016, it was estimated that 200 million people suffered from osteoporosis, and 8.9 million had osteoporotic fractures [7]. Osteoporotic fracture has a high mortality and morbidity, increased cost of social care, and low health-related quality of life [1, 3, 8, 9]. Early detection and interventions such as supplemental calcium and vitamin D intake, bisphosphonates, and monoclonal antibody medications, and exercise (jogging, aerobic dancing, etc.) are suggested in accordance with disease severity for geriatric welfare [10]. According to the World Health Organization (WHO) guideline, osteoporosis diagnostic criteria and categories are based on BMD measurement. In general, dual-energy X-ray absorptiometry (DXA) is a hospital-based examination to estimate the BMD, while disadvantaged by its radiation exposure and limited accessibility in the community. Although various questionnaire tools for screening have been developed, they are limited by inadequate specificity. Bioelectrical impedance analysis (BIA) is a commonly used method for estimating body composition. Therefore, it is possible to improve osteoporosis detection through BIA because of its accessibility in the community.

Fat mass (FM) has a positive correlation with BMD, especially in the elderly [11-13], and is more influential on the BMD than fat-free mass (FFM) be [14, 15]. Some researchers pointed out that FFM is an important predictor for BMD without age restriction $[16,17]$. Our previous study found out the basal metabolic rate (BMR) is closely associated with BMD in elderly persons and claimed BMR might be a predictor for osteoporosis [18]. Based on these results, the relationship between body composition and BMD was clarified, and the parameters of body composition (FFM, FM, FM ratio, and BMR) have the potential to predict BMD. But it is unclear what the cutoff values of FFM, FM, FM ratio, and BMR are for osteoporosis prediction. The prevalence of osteoporosis in women is higher than that in men [19]. Here, we undertook this pilot study to determine the cutoff values of FFM, FM, BMR, and FM ratio from body composition, non-invasive assessment, to predict osteoporosis.

\section{Methods}

\section{Participants}

This cross-sectional study was performed at the Chia-Yi Chang Gung Memorial Hospital. All participants were assessed with the BMD measurement and body composition. Based on the WHO osteoporosis definition, the subjects whose $T$-score $>-2.5$ were divided into the non-osteoporosis group while $T$-score $<-2.5$ into the osteoporosis group. All participants were enrolled from the rural community from southern Taiwan between August 2010 and December 2012. The inclusion criteria were physically independent postmenopausal women aged over 50 years old. The exclusion criteria were women taking any medications predisposing to poor bone quality, undergoing any medical therapies of osteoporosis and hormone-replacement therapy, with cognitive impairment and diabetes mellitus, and having bone fracture history. This study was approved by the Ethics Committee and Institutional Review Board of the Chang Gung Memorial Hospital (IRB 99-3951B) and registered in the ClinicalTrails.gov (ID: NCT02936336). The written informed consent was obtained from all individual participants included in the study.

\section{BMD measurement}

DXA (QDR 4500A; Hologic, Waltham, MA, USA) was performed to measure the BMD of the proximal femur (femoral neck) and lumbar spine (L2-L4) by an experienced and qualified radiographer (Fig. 1). By the definition from the World Health Organization, a BMD Tscore of -2.5 or below is diagnosed as osteoporosis.

\section{Body composition}

An eight-polar tactile-electrode impedance meter (InBody 720, Biospace, Seoul, Korea) was used to assess the body composition and simultaneously recorded body weight, FFM, total body water, regional fat mass, and BMR [18].

\section{Statistical analysis}

Normal distributions were calculated using the ShapiroWilk test. Pearson's correlation analysis was used to calculate the correlation coefficients among variables. By the World Health Organization definition (osteoporosis: $T$-score $\leqq-2.5$; osteopenia: $T$-score $\leqq--1$ and $>-2.5$; normal: $T$-score $>-1)$, the participants in this study were divided into two groups, non-osteoporosis (non-OP) and osteoporosis (OP). A receiver operating characteristic (ROC) curve was plotted with non-OP as positive and $\mathrm{OP}$ as negative to assess the diagnostic value of the predictors FFM, FM, BMR, and FM ratio. The area under the ROC curves (AUC) was calculated to evaluate the predictive performance of the variables. The points on the fit curve closest to the left upper corner were defined 
(A)

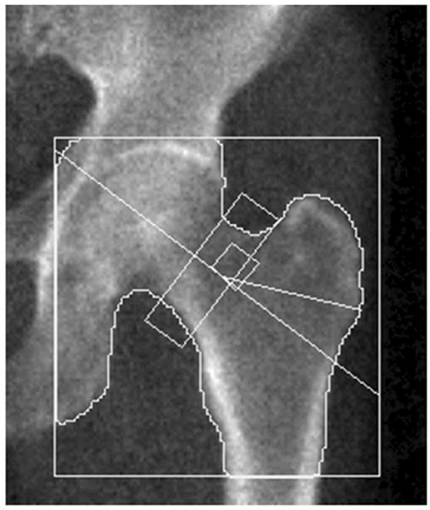

Femoral Neck

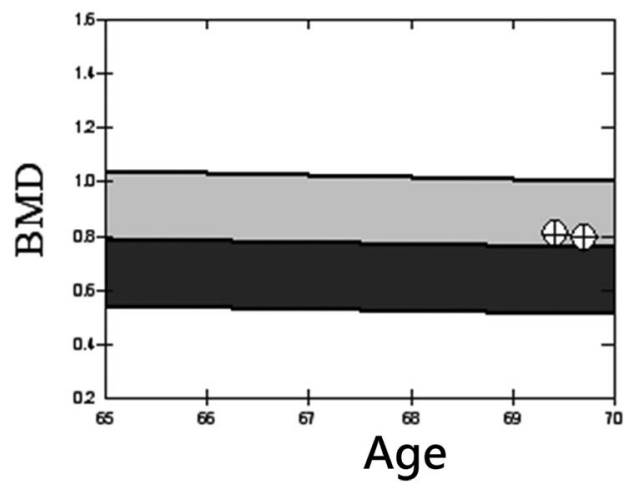

(B)
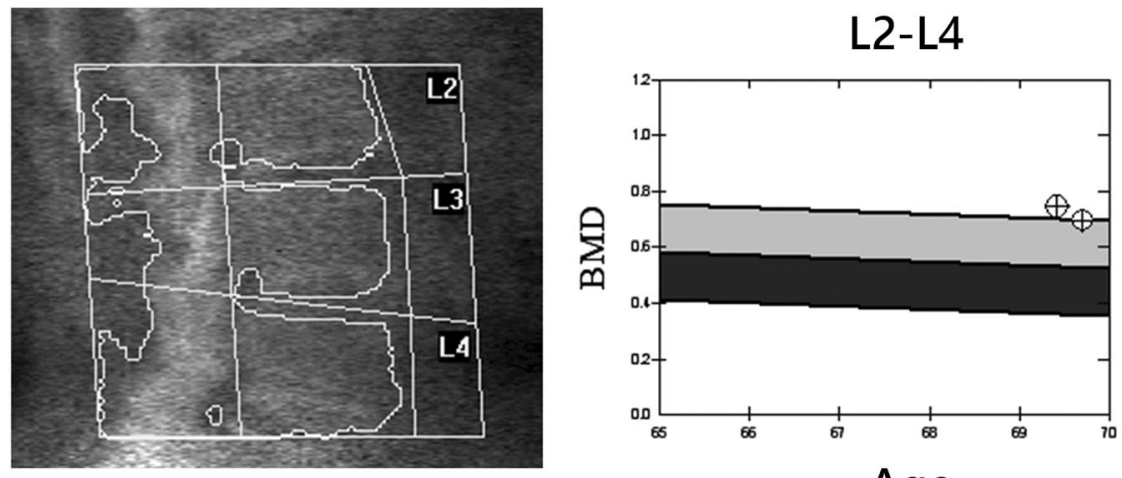

Age

Fig. 1 The example of BMD measurement of the $\mathbf{a}$ femoral neck and $\mathbf{b}$ lumbar spine L2-L4 by DXA in female aged 69

as cutoff points for the diagnosis of osteoporosis. All data analysis was performed using the Statistical Package for the Social Sciences Windows, version 17.0 (SPSS, Chicago, IL, USA). All continuous data were presented as the mean \pm SD. The statistical analysis was performed by $\mathrm{CHF}$.

\section{Results}

Between August 2010 and December 2012, all participants were enrolled from the rural community from southern Taiwan. A total of 363 postmenopausal women over the age of 50 were included in this study. Based on the WHO osteoporosis definition, 211 subjects whose $T$ score $>-2.5$ were classified as non-osteoporosis group and 152 subjects whose $T$-score $<-2.5$ as osteoporosis group. The subjects' demography is shown in Table 1. The average subjects' age is 64.1 years, and body mass index (BMI) is $24.7 \mathrm{~kg} / \mathrm{m}^{2}$. The women had a mean $T$ score of the femur neck and spine of respectively $-1.9 \pm$
1.0 and $-1.8 \pm 1.4$. Their mean FFM, FM, and FM ratio are respectively $38 \pm 4 \mathrm{~kg}, 21.2 \pm 6.3 \mathrm{~kg}$, and $35 \pm 7 \%$, while the mean of BMR is $1182.7 \pm 88.9 \mathrm{kcal}$. Age, height, weight, BMI, femur neck $T$-score (FNTS), spine $T$-score (STS), FFM, FF, and BMR had significant differences between the two groups. So, we assessed the relationship between BMD T-score (femur neck and spine) and other variables by Pearson correlation analysis. As shown in Table 2, age is negatively correlated with FNTS and STS while other variables are positively correlated with FNTS and STS ( $p<0.01$ for all). The correlation coefficient of FFM, FM, FM ratio, and BMR with femur neck $T$-score was $0.373,0.266,0.165$, and 0.369 , respectively, while with spine $T$-score $0.350,0.251,0.166$, and 0.352 , respectively. Meanwhile, we performed a multivariate logistic regression analysis of osteoporosis that showed age, FM ratio, and BMR were significant factors (Supplemental Table 1). 
Table 1 Demographics for subjects $(N=363)$

\begin{tabular}{|c|c|c|c|c|c|c|}
\hline & Total st & 63) & Non-os & 211) & Osteor & 152) \\
\hline & Mean & $\pm S D$ & Mean & $\pm S D$ & Mean & $\pm S D$ \\
\hline Age (years) & 64.1 & \pm 8.3 & 62.0 & \pm 8.0 & 66.9 & $\pm 7.9^{*}$ \\
\hline Height (cm) & 154.7 & \pm 5.2 & 155.5 & \pm 5.3 & 153.5 & $\pm 4.7^{*}$ \\
\hline Weight (kg) & 59.0 & \pm 8.5 & 61.0 & \pm 8.4 & 56.3 & $\pm 8.0^{*}$ \\
\hline BMI & 24.7 & \pm 3.4 & 25.2 & \pm 3.4 & 24.0 & $\pm 3.3^{*}$ \\
\hline FNTS & -1.9 & \pm 1.0 & -1.3 & \pm 0.7 & -2.7 & $\pm 0.7^{*}$ \\
\hline STS & -1.8 & \pm 1.4 & -1.0 & \pm 1.1 & -2.8 & $\pm 1.1^{*}$ \\
\hline FM ratio (\%) & 35.4 & \pm 6.7 & 35.9 & \pm 6.4 & 34.7 & \pm 7.1 \\
\hline FFM (kg) & 37.6 & \pm 4.1 & 38.8 & \pm 4.2 & 36.0 & $\pm 3.4^{*}$ \\
\hline $\mathrm{FF}(\mathrm{kg})$ & 21.2 & \pm 6.3 & 22.2 & \pm 6.2 & 19.9 & $\pm 6.3^{*}$ \\
\hline BMR (kcal) & 1182.7 & \pm 88.9 & 1207.3 & \pm 90.7 & 1148.5 & \pm 73.9 * \\
\hline
\end{tabular}

$B M R$ basal metabolic rate, FFM fat-free mass, FM fat mass, FM ratio fat mass ratio, FNTS femur neck $T$-score, STS spine $T$-score ${ }^{*} p \leq 0.05$ between non-osteoporosis and osteoporosis

ROC curve analysis was performed to estimate the optimal cutoff value of FFM, FM, FM ratio, and BMR for predicting osteoporosis. As shown in Table 3 and Fig. 2, FFM showed an optimal sensitivity (0.588) and specificity $(0.73)$ at the cutoff value of $37.9 \mathrm{~kg}$ (AUC $=0.700$, 95\%CI 0.646-0.753). FM revealed an optimal sensitivity (0.73) and specificity (0.47) at the cutoff value of $18.6 \mathrm{~kg}$ $(\mathrm{AUC}=0.602,95 \% \mathrm{CI} 0.542-0.661)$. BMR presented an optimal sensitivity (0.59) and specificity $(0.73)$ at the cutoff value of $1187.5 \mathrm{kcal}$ (AUC $=0.701,95 \% \mathrm{CI} 0.647-$ 0.754 ) while FM ratio did not statistically predict osteoporosis.

\section{Discussion}

Previous studies reported that FM is related to the BMD of the lumbar spine and proximal femur [20, 21]. Besides, other studies showed that BMR is more closely related to BMD than FFM, FM, and BMI [18, 22, 23]. Our results were echoed to these studies and revealed that BMR could be effective to predict osteoporosis (BMD T-score < -2.5) with the optimal cutoff value of $1187.5 \mathrm{kcal}$ (Table 3 and Fig. 2) in women over 50 years old. If their BMR was lower than the cutoff values $1187.5 \mathrm{kcal}$, they might have a high risk of osteoporosis.

As mentioned above, higher FM went along with higher BMD as an effective predator for osteoporosis, but some studies showed that FM was not effective for osteoporosis prediction in middle-aged and elderly people in Asia [24, 25], and the increased central body FM was negatively associated with BMD [26]. Moreover, Saarelainen and his colleagues reported that trunk FM is positively related to lumbar spine $\mathrm{BMD}$, but not to the hip BMD and body weight in postmenopausal women [21]. Kirchengast and his colleagues found out that the

Table 2 Correlation coefficients between variables and BMD T-score $(r)$

\begin{tabular}{|c|c|c|c|c|c|c|c|c|c|c|}
\hline & FNTS & STS & Age & Height & Weight & BMI & FM ratio & FM & BMR & FFM \\
\hline FNTS & 1 & & & & & & & & & \\
\hline STS & $.619^{* *}$ & 1 & & & & & & & & \\
\hline Age & $-.353^{* *}$ & $-.222^{* *}$ & 1 & & & & & & & \\
\hline Height & $.200^{* *}$ & $.180^{* *}$ & $-.206^{* *}$ & 1 & & & & & & \\
\hline Weight & $.356^{* *}$ & $.345^{* *}$ & -.064 & $.348^{* *}$ & 1 & & & & & \\
\hline BMI & $.255^{* *}$ & $.265^{* *}$ & .029 & $-.123^{*}$ & $.874^{* *}$ & 1 & & & & \\
\hline FM ratio & $.165^{* *}$ & $.166^{* *}$ & .069 & $-.205^{* *}$ & $.646^{* *}$ & $.773^{* *}$ & 1 & & & \\
\hline FM & $.266^{* *}$ & $.251^{* *}$ & .038 & .001 & $.859^{* *}$ & $.894^{* *}$ & $.908^{* *}$ & 1 & & \\
\hline BMR & $.369^{* *}$ & $.352^{* *}$ & $-.151^{* *}$ & $.627^{* *}$ & $.662^{* *}$ & $.387^{* *}$ & -.066 & $.281^{* *}$ & 1 & \\
\hline FFM & $.373^{* *}$ & $.350 * *$ & $-.160^{* *}$ & $.621^{* *}$ & $.665^{* *}$ & $.393^{* *}$ & -.054 & $.284^{* *}$ & $.995^{* *}$ & 1 \\
\hline
\end{tabular}

BMR basal metabolic rate, FFM fat-free mass, FM fat mass, FM ratio fat mass ratio, FNTS femur neck $T$-score, STS spine $T$-score ${ }^{*} p \leq 0.05$

${ }^{* *} p \leq 0.01$ 
Table 3 Area under the curve (AUC) of BMR, fat-free mass, and fat mass as a single predictor for each measurement site from ROC analysis

\begin{tabular}{lllllll}
\hline Variable & AUC & Cut-point & $\begin{array}{l}\text { 1- } \\
\text { specificity }\end{array}$ & & Sensitivity & \multicolumn{2}{c}{$\mathbf{9 5 . 0 \%}$ Cl } \\
\cline { 5 - 7 } & & & & Lower & Upper \\
\hline FFM & $.700^{* *}$ & $37.9 \mathrm{~kg}$ & .270 & .588 & .646 & .753 \\
FM & $.602^{* *}$ & $18.6 \mathrm{~kg}$ & .533 & .730 & .542 & .661 \\
FM ratio & .538 & $26.7 \%$ & .829 & .934 & .477 & .599 \\
BMR & $.701^{* *}$ & $1187.5 \mathrm{kcal}$ & .270 & .597 & .647 & .754 \\
\hline
\end{tabular}

FFM fat-free mass, FM fat mass, $F M$ ratio fat mass ratio, BMR basal metabolic rate

${ }^{* *} p<0.01$

relationship between FM and BMD only occurred in elder women [27]. These studies showed that the FM for osteoporosis prediction might be restricted by ethnicity, gender, the region of FM, etc. However, FFM has a stronger positive relation with BMD at all ages in Chinese men and women [28], and our results (Table 3) also showed that the AUC of FFM (0.700) was higher than FM (0.602), suggesting that FFM seems to be better than FM for osteoporosis prediction. However, BMD is influenced by multiple factors such as genetic factors, gender, diet physical activity, medical diseases, and stress [5, 29]. It seemed the BMR is not the sole determinant factor for osteoporosis that the correlation coefficient between all body composition variable and BMD $T$-score was < 0.4. However, it did provide a window for screening osteoporosis through a convenient and non-invasive methodology.
BMR, the amount of energy expended, is predicted with regard to resting energy expenditure. In multivariate analysis, BMR was low correlated with FM (correlation coefficient 0.281) (Table 2), suggesting that BMR and FM might be independent predictors of osteoporosis. However, BMR is more closely associated with BMD in elderly persons than BMI, FM, and FFM [18, $22,23]$. BMR is positively associated with muscle strength [30] while muscle strength and BMD also are correlated [31, 32]. Our results also showed that the AUC of BMR is higher than FFM and FM, suggesting that BMR might be a good predictor for osteoporosis. According to our results, we proposed that if the postmenopausal woman's BMR is lower than the cutoff value, $1187.5 \mathrm{kcal}$, the subject might have a higher osteoporosis risk than others with over $1187.5 \mathrm{kcal}$. Although hip and spine fractures are a portion of osteoporotic fractures, these fractures have a huge impact on the patient's daily activity and medical burden [33, 34]. Low BMD is associated with an increased risk of fracture and hence provided a measurable method in osteoporotic fracture preventions. However, the disadvantages are radiation exposure and limited accessibility. Since BMR could well predict BMD in the present study, it seemed a good method in screening osteoporosis. Besides, the American College of Sports Medicine (ACSM) proposes that increasing physical exercise can maintain and improve bone quality in response to bone health problems [35]. Here, we provided the cutoff value of $1187.5 \mathrm{kcal}$ of BMR. It could serve as a target value for exercise

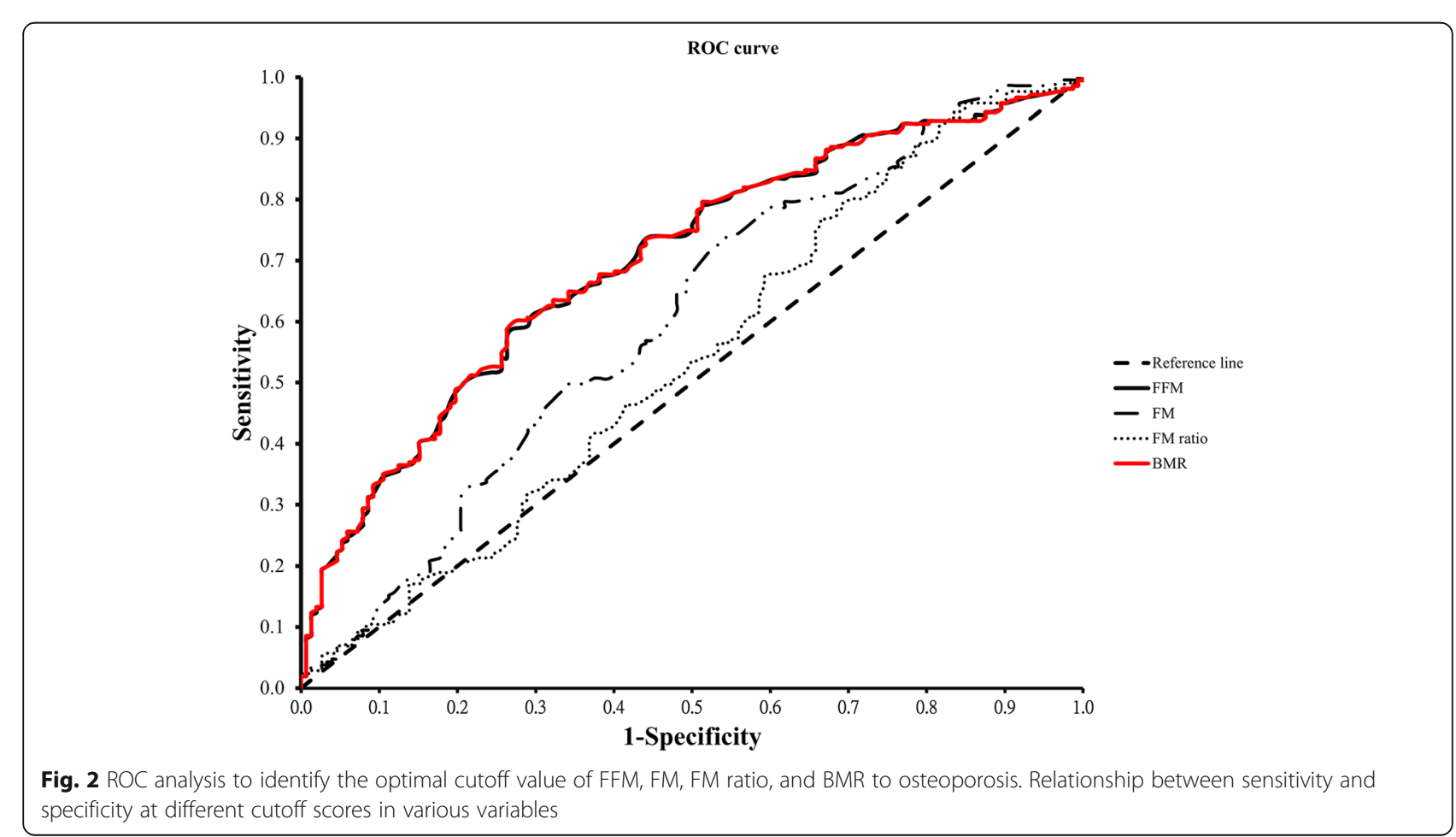


intervention to enhance BMR in postmenopausal women to maintain and improve their BMD.

Several limitations of the present study should be acknowledged. First, the subjects of this study are postmenopausal women aged over 50 years old. Men and those under 50 years old are not included. Therefore, the relevant threshold only applies to postmenopausal women aged over 50 years old. Second, because the subjects were from southern Taiwan, the present cutoff value was restricted to Asians. It was shown that the body compositions were not identical between Caucasian and Asian populations [36-38]. In fact, Asian populations had more fat mass percentage and central fat. Therefore, extrapolating the findings in the present study to Caucasian populations warranted further investigations. Nevertheless, the effect of the exercise on the BMD has no difference in different races, so we proposed that the BMR could be a predictor for BMD in different races via slightly adjusting the cutoff value of BMR.

\section{Implications for practice Conclusions}

In the present study, our results showed that BMR was a better predictor for osteoporosis than other body compositions, including FM, FM ratio, and FFM. We proposed that the BMR could serve as a screening tool to alert the risk of osteoporosis and early intervention for osteoporosis. Simultaneously, the cutoff value of BMR also could be a target value for exercise intervention to enhance BMR in postmenopausal women to maintain or improve their BMD. In addition, clinical risk assessment instruments, such as Osteoporosis Self-Assessment Tool, the Simple Calculated Osteoporosis Risk Estimation instrument, the Osteoporosis Self-Assessment Tool for Asians, and the Osteoporosis Risk Assessment Instrument, all had high sensitivity exceeding $90 \%$ for identifying individuals with DXA-determined osteoporosis or low BMD but low specificity at thresholds required for high sensitivity [39]. It is possible to include this objective data such as BMR to enhance sensitivity and specificity in osteoporosis screening.

\section{Abbreviations}

BMD: Bone mineral density; FFM: Fat-free mass; FM: Fat mass; BMR: Basal metabolic rate; ROC: Receiver operating characteristic; AUC: Area under the ROC curves; BMI: Body mass index; ACSM: American College of Sports Medicine

\section{Supplementary Information}

The online version contains supplementary material available at https://doi. org/10.1186/s13018-021-02351-3.

Additional file 1: Supplemental Table 1. Multivariate logistic

regression analysis for predicting osteoporosis.
Authors' contributions

WHH and WBH drafted the manuscript and revised it critically for important intellectual content. WBH and CHF analyzed and interpreted the data. WHH and RWWH contributed substantially to the conception and design of the study. All authors read and approved the final manuscript.

\section{Funding}

This work was supported by Chang Gung Memorial Hospital Grant CMRP G690111-3 and CORPG6F0011-13 which are appreciated. There was no external funding.

\section{Availability of data and materials}

The datasets used and/or analyzed during the current study are available from the corresponding author on reasonable request.

\section{Declarations}

Ethics approval and consent to participate

This retrospective study was approved by the Ethics Committee and Institutional Review Board of the Chang Gung Memorial Hospital (IRB 993951B), and all patients provided written informed consent. The study protocol was also registered in the ClinicalTrails.gov (ID: NCT02936336).

\section{Consent for publication}

Not applicable

\section{Competing interests}

All authors declare that they have no competing interests.

\section{Author details}

'Department of Orthopaedic Surgery, Chang Gung Memorial Hospital, No. 6, West Section, Chia-Pu Road, Pu-Tz City, Chiayi 613, Taiwan. ${ }^{2}$ School of Medicine, Chang Gung University, Taoyuan City, Taiwan. ${ }^{3}$ Sports Medicine Center, Chang Gung Memorial Hospital, No. 6, West Section, Chia-Pu Road, Pu-Tz City, Chiayi 613, Taiwan.

Received: 15 July 2020 Accepted: 10 March 2021

Published online: 24 March 2021

\section{References}

1. Cauley JA. Public health impact of osteoporosis. J Gerontol A Biol Sci Med Sci. 2013;68(10):1243-51. https://doi.org/10.1093/gerona/glt093.

2. Schmitt NM, Schmitt J, Doren M. The role of physical activity in the prevention of osteoporosis in postmenopausal women-an update. Maturitas. 2009;63(1):34-8. https://doi.org/10.1016/..maturitas.2009.03.002.

3. Compston J, Cooper A, Cooper C, Francis R, Kanis JA, Marsh D, McCloskey E, Reid DM, Selby P, Wilkins M, National Osteoporosis Guideline Group (NOGG). Guidelines for the diagnosis and management of osteoporosis in postmenopausal women and men from the age of 50 years in the UK. Maturitas. 2009;62(2):105-8. https://doi.org/10.1016/..maturitas.2008.11.022.

4. Hernlund E, Svedbom A, Ivergard M, Compston J, Cooper C, Stenmark J, et al. Osteoporosis in the European Union: medical management, epidemiology and economic burden. A report prepared in collaboration with the International Osteoporosis Foundation (IOF) and the European Federation of Pharmaceutical Industry Associations (EFPIA). Arch Osteoporos. 2013;8:136.

5. Vondracek SF, Hansen LB, McDermott MT. Osteoporosis risk in premenopausal women. Pharmacotherapy. 2009;29(3):305-17. https://doi. org/10.1592/phco.29.3.305.

6. Biz C, Berizzi A, Crimi A, Marcato C, Trovarelli G, Ruggieri P. Management and treatment of femoral neck stress fractures in recreational runners: a report of four cases and review of the literature. Acta Biomed. 2017;88(4S): 96-106. https://doi.org/10.23750/abm.v88i4-S.6800.

7. Pisani P, Renna MD, Conversano F, Casciaro E, Di Paola M, Quarta E, et al. Major osteoporotic fragility fractures: risk factor updates and societal impact. World J Orthop. 2016;7(3):171-81. https://doi.org/10.5312/wjo.v7.i3.171.

8. Johnell $\mathrm{O}$, Kanis JA. An estimate of the worldwide prevalence and disability associated with osteoporotic fractures. Osteoporos Int. 2006;17(12):1726-33. https://doi.org/10.1007/s00198-006-0172-4.

9. Wang CB, Lin CF, Liang WM, Cheng CF, Chang YJ, Wu HC, et al. Excess mortality after hip fracture among the elderly in Taiwan: a nationwide population-based cohort study. Bone. 2013;56(1):147-53. https://doi.org/10.1016/j.bone.2013.05.015. 
10. Tu KN, Lie JD, Wan CKV, Cameron M, Austel AG, Nguyen JK, van K, Hyun D. Osteoporosis: a review of treatment options. P T. 2018;43(2):92-104.

11. Cui LH, Shin MH, Kweon SS, Park KS, Lee YH, Chung EK, Nam HS, Choi JS. Relative contribution of body composition to bone mineral density at different sites in men and women of South Korea. J Bone Miner Metab. 2007;25(3):165-71. https://doi.org/10.1007/s00774-006-0747-3.

12. Gonnelli S, Caffarelli C, Tanzilli L, Alessi C, Tomai Pitinca MD, Rossi S, Campagna MS, Nuti R. The associations of body composition and fat distribution with bone mineral density in elderly Italian men and women. J Clin Densitom. 2013;16(2):168-77. https://doi.org/10.1016/j.jocd.2012.02.013.

13. Lekamwasam S, Weerarathna T, Rodrigo M, Arachchi WK, Munidasa D. Association between bone mineral density, lean mass, and fat mass among healthy middle-aged premenopausal women: a cross-sectional study in southern Sri Lanka. J Bone Miner Metab. 2009;27(1):83-8. https://doi.org/10.1 007/s00774-008-0006-x.

14. Douchi T, Yamamoto S, Oki T, Maruta K, Kuwahata R, Yamasaki H, Nagata Y. Difference in the effect of adiposity on bone density between pre- and postmenopausal women. Maturitas. 2000;34(3):261-6. https://doi.org/10.101 6/S0378-5122(99)00114-0.

15. Douchi T, Yonehara Y, Kawamura Y, Kuwahata A, Kuwahata T, Iwamoto I. Difference in segmental lean and fat mass components between pre- and postmenopausal women. Menopause. 2007;14(5):875-8. https://doi.org/10.1 097/gme.0b013e318032b2f9.

16. Cheng Q, Zhu YX, Zhang MX, Li LH, Du PY, Zhu MH. Age and sex effects on the association between body composition and bone mineral density in healthy Chinese men and women. Menopause. 2012;19(4):448-55. https:// doi.org/10.1097/gme.0b013e31823a40ba.

17. Genaro PS, Pereira GA, Pinheiro MM, Szejnfeld VL, Martini LA. Influence of body composition on bone mass in postmenopausal osteoporotic women. Arch Gerontol Geriatr. 2010;51(3):295-8. https://doi.org/10.1016/j.archger.2 009.12 .006$.

18. Hsu WH, Fan $\mathrm{CH}$, Lin ZR, Hsu RW. Effect of basal metabolic rate on the bone mineral density in middle to old age women in Taiwan. Maturitas. 2013;76(1):70-4. https://doi.org/10.1016/j.maturitas.2013.05.016.

19. Wade SW, Strader C, Fitzpatrick LA, Anthony MS, O'Malley CD. Estimating prevalence of osteoporosis: examples from industrialized countries. Arch Osteoporos. 2014;9(1):182-92. https://doi.org/10.1007/s11657-014-0182-3.

20. Nur H, Toraman NF, Arica Z, Sarier N, Samur A. The relationship between body composition and bone mineral density in postmenopausal Turkish women. Rheumatol Int. 2013;33(3):607-12. https://doi.org/10.1007/s00296012-2391-7.

21. Saarelainen J, Honkanen $\mathrm{R}$, Kroger $\mathrm{H}$, Tuppurainen M, Jurvelin JS, Niskanen L. Body fat distribution is associated with lumbar spine bone density independently of body weight in postmenopausal women. Maturitas. 2011; 69(1):86-90. https://doi.org/10.1016/j.maturitas.2011.02.009.

22. Yilmaz B, Yasar E, Goktepe AS, Onder ME, Alaca R, Yazicioglu K, et al. The relationship between basal metabolic rate and femur bone mineral density in men with traumatic spinal cord injury. Arch Phys Med Rehabil. 2007;88(6): 758-61. https://doi.org/10.1016/j.apmr.2007.02.037.

23. Quirino MA, Modesto-Filho J, de Lima Vale SH, Alves CX, Leite LD, BrandaoNeto J. Influence of basal energy expenditure and body composition on bone mineral density in postmenopausal women. Int J Gen Med. 2012;5: 909-15. https://doi.org/10.2147/IJGM.S36823.

24. Kim JH, Choi HJ, Kim MJ, Shin CS, Cho NH. Fat mass is negatively associated with bone mineral content in Koreans. Osteoporos Int. 2012;23(7):2009-16. https://doi.org/10.1007/s00198-011-1808-6.

25. Yoo HJ, Park MS, Yang SJ, Kim TN, Lim KI, Kang HJ, Song W, Baik SH, Choi DS, Choi KM. The differential relationship between fat mass and bone mineral density by gender and menopausal status. J Bone Miner Metab. 2012;30(1):47-53. https://doi.org/10.1007/s00774-011-0283-7.

26. Fu X, Ma X, Lu H, He W, Wang Z, Zhu S. Associations of fat mass and fat distribution with bone mineral density in pre- and postmenopausal Chinese women. Osteoporos Int. 2011;22(1):113-9. https://doi.org/10.1007/s00198-01 0-1210-9.

27. Kirchengast S, Huber J. Sex-specific associations between soft tissue body composition and bone mineral density among older adults. Ann Hum Biol. 2012;39(3):206-13. https://doi.org/10.3109/03014460.2012.676067.

28. Hu WW, Zhang H, Wang C, Gu JM, Yue H, Ke YH, Hu YQ, Fu WZ, Li M, Zhang ZL. Lean mass predicts hip geometry and bone mineral density in Chinese men and women and age comparisons of body composition. J Clin Densitom. 2012;15(4):434-42. https://doi.org/10.1016/j.jocd.2012.02.004.
29. Pouresmaeili F, Kamalidehghan B, Kamarehei M, Goh YM. A comprehensive overview on osteoporosis and its risk factors. Ther Clin Risk Manag. 2018;14: 2029-49. https://doi.org/10.2147/TCRM.S138000.

30. Oh SK, Son DH, Kwon YJ, Lee HS, Lee JW. Association between basal metabolic rate and handgrip strength in older Koreans. Int J Environ Res Public Health. 2019;16(22):4377-89. https://doi.org/10.3390/ijerph16224377.

31. Rikkonen T, Sirola J, Salovaara K, Tuppurainen M, Jurvelin JS, Honkanen R, Kröger $\mathrm{H}$. Muscle strength and body composition are clinical indicators of osteoporosis. Calcif Tissue Int. 2012;91(2):131-8. https://doi.org/10.1007/ s00223-012-9618-1.

32. Chen L, Nelson DR, Zhao Y, Cui Z, Johnston JA. Relationship between muscle mass and muscle strength, and the impact of comorbidities: a population-based, cross-sectional study of older adults in the United States. BMC Geriatr. 2013;13(1):74-82. https://doi.org/10.1186/1471-2318-13-74.

33. Cannada LK, Hill BW. Osteoporotic hip and spine fractures: a current review. Geriatr Orthop Surg Rehabil. 2014;5(4):207-12. https://doi.org/10.1177/21514 58514548579

34. Bano G, Dianin M, Biz C, Bedogni M, Alessi A, Bordignon A, Bizzotto M, Berizzi A, Ruggieri P, Manzato E, Sergi G. Efficacy of an interdisciplinary pathway in a first level trauma center orthopaedic unit: a prospective study of a cohort of elderly patients with hip fractures. Arch Gerontol Geriatr. 2020;86:103957. https://doi.org/10.1016/j.archger.2019.103957.

35. Kohrt WM, Bloomfield SA, Little KD, Nelson ME, Yingling VR, American College of Sports M. American college of sports medicine position stand: physical activity and bone health. Med Sci Sports Exerc. 2004;36(11):198596. https://doi.org/10.1249/01.MSS.0000142662.21767.58.

36. Liang MT, Bassin S, Dutto D, Braun W, Wong N, Pontello AM, et al. Bone mineral density and leg muscle strength in young Caucasian, Hispanic, and Asian women. J Clin Densitom. 2007;10(2):157-64. https://doi.org/10.1016/j. jocd.2006.12.005.

37. Morimoto Y, Maskarinec G, Conroy SM, Lim U, Shepherd J, Novotny R. Asian ethnicity is associated with a higher trunk/peripheral fat ratio in women and adolescent girls. J Epidemiol. 2012;22(2):130-5. https://doi.org/10.2188/ jea.JE20110100.

38. Hunma S, Ramuth H, Miles-Chan JL, Schutz Y, Montani JP, Joonas N, Dulloo AG. Body composition-derived BMI cut-offs for overweight and obesity in Indians and Creoles of Mauritius: comparison with Caucasians. Int J Obes. 2016;40(12):1906-14. https://doi.org/10.1038/ijo.2016.176.

39. Nayak S, Edwards DL, Saleh AA, Greenspan SL. Systematic review and metaanalysis of the performance of clinical risk assessment instruments for screening for osteoporosis or low bone density. Osteoporos Int. 2015;26(5): 1543-54. https://doi.org/10.1007/s00198-015-3025-1.

\section{Publisher's Note}

Springer Nature remains neutral with regard to jurisdictional claims in published maps and institutional affiliations.
Ready to submit your research? Choose BMC and benefit from:
- fast, convenient online submission
- thorough peer review by experienced researchers in your field
- rapid publication on acceptance
- support for research data, including large and complex data types
- gold Open Access which fosters wider collaboration and increased citations
- maximum visibility for your research: over $100 \mathrm{M}$ website views per year
At BMC, research is always in progress.
Learn more biomedcentral.com/submissions 